\title{
Threat, its impacts over survival systems, and related behavioral disorders
}

\author{
Nickolas Carui, Luis Fernando de Almeida, Gabriela Miglioranza, Felipe Corchs
}

Carui N, Almeida LF, Miglioranza G, Corchs F. Threat, its impacts over survival systems, and related behavioral disorders. Rev Med (São Paulo). 2019 July-Aug.;98(4):267-72.

\begin{abstract}
Defensive and appetitive motivation systems have evolved to propitiate more sophisticated interactions with environment threats and needs, such as nutrients, water, reproduction, and temperature regulation. In contact with survivalrelevant environmental stimuli, organisms change as a whole to maximize fitness to that occasion. In this paper, an overview on defensive systems is described, as well as some relevant aspects of defensive states, including their impacts over appetitive functions. A parallel between these characteristics and what is called threatrelated disorders in the present paper is drawn and, finally, these similarities are used as basis for a theoretical proposition that at least part of these disorders can be seen as persistent states of defense.
\end{abstract}

Keywords: Survival/psychology; Mental disorders/psychology.

\section{INTRODUCTION}

$\mathrm{B}$ asic survival functions, such as defense, energy and water maintenance, reproduction, and temperature regulation, as well as the brain circuits involved in these functions, have been strongly implicated in the behavioral problems approached by psychiatry ${ }^{1-3}$. Despite having a long history in scientific psychology and neuroscience, approaching psychiatric disorders in these terms is a considerably new enterprise $e^{4}$. In the present paper, some important organismic changes observed in response to threats, as well as their relationships with psychiatric conditions will be discussed. As the organism react as a whole to these survival contingencies, rather than having compartmentalized responses and systems
RESUMO: Funções de sobrevivência e sistemas orgânicos relacionados evoluíram para propiciar interações mais sofisticadas com ameaças ambientais e necessidades individuais, tais como nutrientes, água, reprodução e regulação da temperatura. Apesar de o termo "sistema" sugerir ações independentes de circuitos em face de tais estímulos, evidências sugerem que os organismos se alteram como um todo em situações relevantes para a sobrevivência, maximizando sua adequação à ocasião. No presente artigo, é apresentada uma visão global de tais alterações organísmicas em face de ameaças, bem como o impaco dessas alterações sobre funções apetitivas. Traça-se, também, um paralelo entre essas características e os transtornos relativos a ameaças. Por fim, as similaridades apontadas servirão como base para uma proposição teórica segundo a qual ao menos parte desses transtornos pode ser entendida como estados permanentes de defesa.

Descritores: Sobrevida/psicologia; Transtornos mentais/ psicologia.

that operate independently for each of these functions, the impact of threatening contingencies over the other basic survival functions will also be discussed in the present paper in order to draw a more adequate picture of the actual phenomena. To that end, survival functions and related systems will be organized into two main groups, namely the defensive function, the main object of the paper, and the appetitive functions, which encompasses consummatory behavior, usually requiring approach and reward or positive reinforcement, such as food, water, and sex. It can be assumed that they form the basis for the negative and positive valence systems, respectively, of the Research Domain Criteria (RDoC) initiative, organized by the United States National Institute of Mental Health (NIMH), the most important initiative for the reorganization of psychiatric classification ${ }^{4}$.

Faculty of Medicine, University of São Paulo. ORCID: Carui N - https://orcid.org/0000-0001-5495-4334; Almeida LF - https://orcid.org/0000-00026738-9167; Miglioranza G - https://orcid.org/0000-0001-8835-8354; Corchs F - https://orcid.org/0000-0002-9935-5658. Email: nickolas.carui@fm.usp. br; luis.a@fm.usp.br; gabriela.miglioranza@fm.usp.br

Correspondence: Felipe Corchs. R. Dr. Ovidio Pires de Campos, 785 - IPq-HC-FMUSP. 05403-010 - São Paulo, SP, Brazil. E-mail: felipe.corchs@ usp.br; felipe.corchs@hotmail.com. 
Carui N, et al. Threat, its impacts over survival systems, and related behavioral disorders.

\section{Defensive systems}

The organismic changes described above to optimize performance in the interaction with survival contingencies in general has been called global organismic states ${ }^{1,3}$, to emphasize the systemic and temporary nature of the process. The term Defensive Motivational States (DMSs) has been used by some authors to describe the organismic changes observed in threatened organisms ${ }^{1-3}$. In this section of the paper, we briefly describe how it works and draw a parallel with biobehavioral characteristics of related psychiatric disorders. This similarity, between DMSs and related disorders, is the basis for the theoretical proposal of threat-related disorders as persistent $\mathrm{DMSs}^{2}$ described at the end of this paper. Among the many defensive processes known to date, the present paper will focus on those with the most illustrative characteristics to describe their relationships with related psychiatric disorders.

A core feature of DMSs is an increased sensitivity to subsequent threats ${ }^{5}$, which is supposed to facilitate early and strong defensive responses. This process is thought to happen in response to both unconditioned threatening stimuli (Unconditioned Stimulus; US), such as a natural predator or painful stimuli, and to learned threats (Conditioned Stimulus; CS). One can learn about threats in the world by many means, but one of the most basic and essential ways is a process known as Pavlovian conditioning, in homage to the Russian physiologist Ian Pavlov who first described the phenomenon ${ }^{6}$. The process, frequently used as a model of threat learning, occur through paired presentations of a neutral stimulus with the threatening US such that the organism learns that this stimulus predicts the US, so they learn to respond defensively to the (now) $\mathrm{CS}^{7}$.

This process involves neuroplasticity in many brain regions, but the amygdala has been the most extensively studied. Information regarding the CS and the US converge in the amygdala at the basolateral nucleus, where plasticity appears to occur ${ }^{3}$. More recently, synaptic plasticity was shown to occurs in specific central amygdala circuits as well ${ }^{8}$, an area that receives outputs from the basolateral amygdala and connects with the brain stem, bringing about physiological changes. Outputs from the basolateral amygdala to the central nucleus and, from there, to the periaqueductal grey matter (PAG), in the brain steam, has been related to more species-specific and reflexive defensive reactions, such as freezing ${ }^{3}$. More recently, it was observed that outputs from the basal nuclei of the amygdala to the shell of the nucleus accumbens (NAcc) are involved in learned and sophisticated defensive responses, usually a form of conditioned active avoidance ${ }^{9}$. See Figure 1 for a schematic representation.

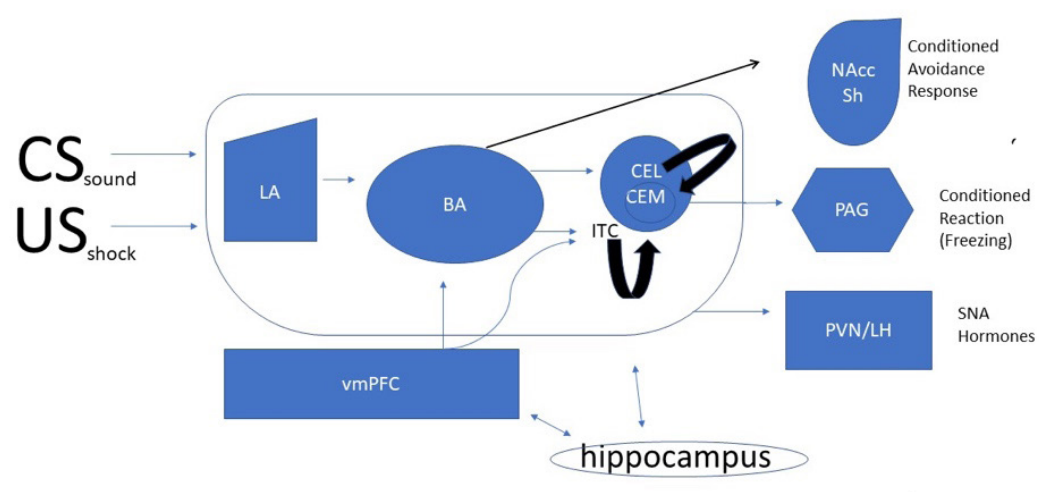

Figure 1: CS - conditioned stimulus; US - snconditioned stimulus; LA - lateral amygdala; BA - basal amygdala, vmPFC - ventral medial pre-frontal cortex; ITC - intercalated cells; CEL - lateral nucleus of central amygdala; CEM - medial nucleus of central amygdala; PVN - paraventricular nucleus (hypothalamus); LH- lateral hypothalamus. During threat conditioning, the CS and the US converge in the amygdala. After several parings, the CS alone will evoke an answer. Reaction like freezing are set through connections with the periaqueductal gray matter (PAG), whereas learned active avoidances depend on the connections of the Basal and Lateral nuclei of the amygdala with de Nucleus Accumbens (NAcc) Shell

On the other hand, different areas of the brain have regulatory function over the amygdala and other subcortical regions involved in the expression of defense. Each specific area and its participation in the final defensive outcome vary depending on many variables such as the specific function and imminence of the threat. When threat imminence is low, more sophisticated defenses that prevent the reduction of the imminence are predominant ${ }^{10,11}$. Cortical structures, especially the ventromedial portion of the prefrontal cortex (vmPFC), inhibit subcortical structures, like the amygdala ${ }^{12}$, which would be related to more reflexive defenses, as freezing and flight, allowing 
the occurrence of learned defenses through the involvement of the NAcc ${ }^{9}$. Therefore, in these situations, the cortical regulatory structures will be strongly activated, whereas the subcortical structures involved in the expression of defensive reactions will have their activation inhibited. As the threat becomes more imminent, such an inhibition loosens up, allowing subcortical structures to activate and more reflexive and species-specific responses to occur ${ }^{10,11}$.

Very similar top-down regulation of the amygdala by cortical structures such as the vmPFC occur in other regulatory processes, such as the extinction of defensive responses $^{7}$. Extinction of defensive responses occurs when unpaired presentations of the CS occur repeatedly such that the organism learns that the CS no longer predicts the US in that context and occasion. During the initial phases of extinction, sometimes referred to as extinction training, changes similar to long term potentiation, a strengthening of the synapsis connections, appear in those pathways ${ }^{13}$. Then, projections to the amygdala activate glutamatergic intercalated cells, which, in its turn, inhibits de central amygdala, competing with the activation of the basolateral nucleus ${ }^{14}$. Even after extinction is learned, if some time passes without contact with the CS, new presentations of this stimulus may elicit defensive responses again. This phenomenon is known as spontaneous recovery and its occurrence is regulated by the vmPFC, which inhibit amygdala activity through connections between these two structures ${ }^{7,15}$.

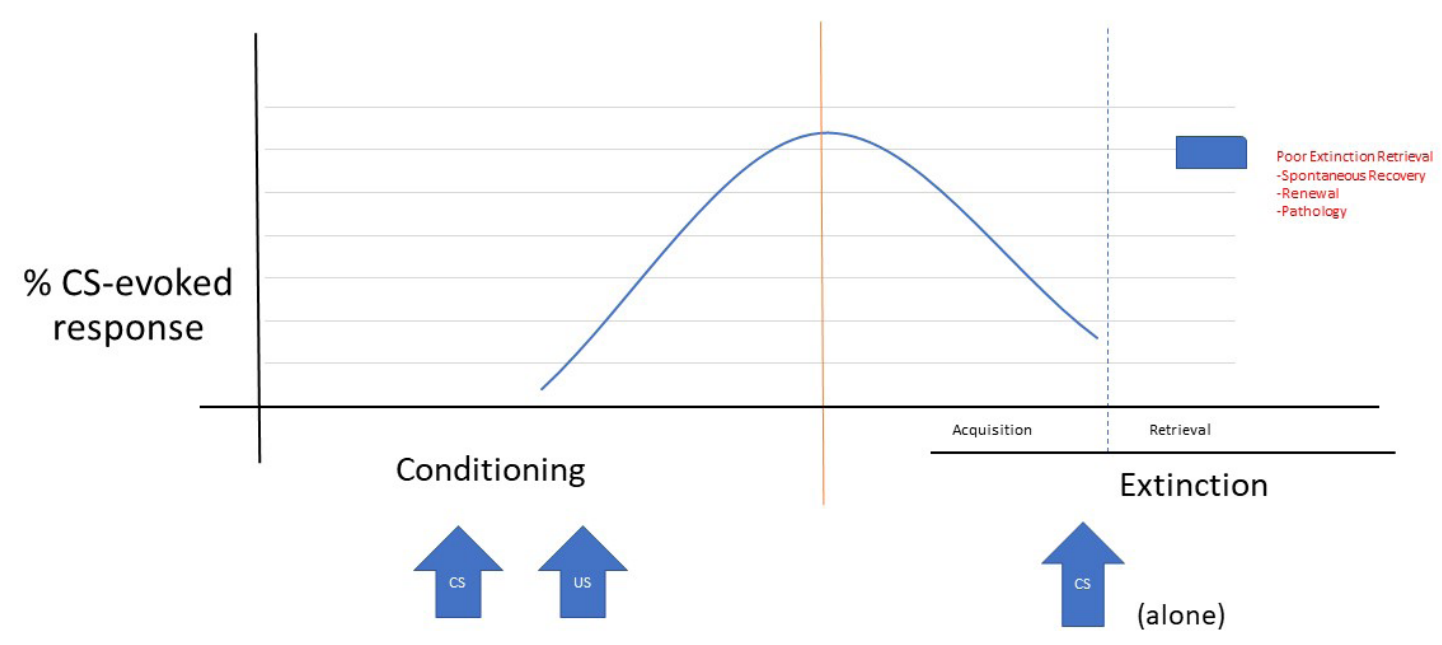

TIME

Figure 2. After threat conditioning, extinction training starts with the unpaired presentation of the CS. Extinction retrieval is necessary when the CS reappears after a period of absence (spontaneous recovery) or in a presentation in a different context (renewal). In some disorders, failure to retrieve extinction is a core characteristic of the condition, probably related to hypo-functional vmPFC and hippocampus. Figure adapted from ${ }^{14}$

The hippocampus takes part in this balance between responding defensively or not to a CS as a function of the context. When an organism learns threat extinction in a specific context, it tends to respond to the CS again if it is presented in a different context. This recovery of previously extinguished responses is known as renewal ${ }^{16}$. Both spontaneous recovery and renewal are processes supposed to have a "better safe than sorry" strategy as nothing is known about the US predictive property of the $\mathrm{CS}$ in contexts and occasions that are not those when and where extinction took place. Whereas the vmPFC is known to modulate the amygdala activity in both situations, the hippocampus was shown to regulate the balance between these two structures as a function of the context ${ }^{17}$. Similarly, through generalization and discrimination of the CS and other stimuli that were present in the context where threat conditioning took place, the hippocampus work by weighting the best tradeoff between responding defensively or not to a broader range of variation of the original stimuli, a process known as generalization.

Finally, the bed nucleus of stria terminalis (BNST) is thought to play a role in an unpredictability context, sustaining our defense response in a threat persistence ${ }^{18}$. Studies with functional magnetic resonance found a signal of BNST with increased activation across conditions as a function of anxiety, growing with the unpredictability of the stimuli ${ }^{19}$. 


\section{Defense system in psychiatric disorders}

Fundamentally, all the structures and systems described above have their idiosyncrasies in psychiatric disorders related to threats and defense*. An increased sensitivity to threats observed in these cases is probably behind the marked rise in threat vigilance and cognitive bias toward threats observed in disorders such as anxiety, depression, and trauma-related disorders ${ }^{21}$, as well as the corresponding biological characteristic, chiefly the hyper-(re)activity of the amygdala also observed in these disorders ${ }^{22}$.

Moreover, patients with Post-traumatic Stress Disorder (PTSD) also show hypo-(re)activativity of the $\mathrm{vmPFC}^{23}$. As mentioned above, the vmPFC participates in the inhibition structures involved in the expression of defense, like the amygdala, in many processes in which these responses should be regulated, as in the case of extinction. Therefore, in conditions in which this mechanism is hypo-(re)active, such as in PTSD, defensive responses, which are already hyperintense, will also be poorly regulated ${ }^{22}$.

Finally, subjects with these disorders have abnormal hippocampal function, poor threat contextualization, and facilitated threat generalization ${ }^{17}$ and, therefore, are always responding defensively to CSs that are only really threatening in specific contexts and to stimuli that only weakly resemble the original CS.

\section{The appetitive system under threat}

As mentioned above, when an organism faces a survival-relevant contingency, the organism changes as a whole to maximize performance in that interaction rather than having a biobehavioral system that works independently to that function. Therefore, even though the focus of the present paper is threat and defense, the impact of threats over other the other survival functions, as well as related organismic systems, need to be approached in order to have a better description of the complete phenomenon.

Roughly, appetitive motivation concerns behavior directed towards goals which are usually associated with rewards, such as food, water and sex. These stimuli usually involve approach towards them usually work as positive reinforcers, i.e., their obtainment usually reinforces the responses that produced them ${ }^{24}$.

In 1954, James Olds and Peter Milner reported a study in which rats would press a lever to obtain brief stimulations in specific brain regions ${ }^{25}$. Not only this region was shown to have properties that were similar to those observed when different forms of appetitive stimuli were given as a consequence of an operant response, such as food, water, and sex, but it was, actually, even more reinforcing than those traditional and natural reinforcers. Although it is known today that different regions of the brain interact in specific manners to each sort of reinforcer, these findings suggested the existence of a common system that would be operate in, essentially, any positive reinforcement process.

After extensive research in the area, it was observed that the areas initially found to have reinforcing properties if stimulated were actually part of broader system, involving multiple neural elements involved ${ }^{26}$. In general terms, reward and positive reinforcement, in the case of operant behavior, involves activity in the mesocorticolimbic system, which is constituted by dopaminergic projections form the ventral tegmental area (VTA) and their projections to nucleus NAcc, amygdala, PFC, and other forebrain regions ${ }^{27}$. Dopaminergic stimulation of the NAcc by inputs from the VTA, sometimes referred to as the mesolimbic system, is a key occurrence related to reward and reinforcement processes, as well as motivation towards rewards ${ }^{27}$. Interestingly, the participation of the system in the subjective pleasure experienced in these processes has been a matter of debate ${ }^{27,28}$.

Recent findings have suggested that reward processing is different in some psychiatric conditions ${ }^{29}$. The fact that these particularities strongly resemble those observed in organisms under threat (see below) led some author to propose that at least part of these disorders could also be seen as forms of threat-related disorders ${ }^{2,28}$. Among the most important findings observed in appetitive-related functions and systems of disorders that are supposedly to be more directly related to threats are the blunted anticipatory experience of pleasure, overly conservative calculation of cost/benefit ratios, and deficits in reinforcement learning observed in depression ${ }^{28}$. Furthermore, neuroimaging studies have been shown that depressed patients have reduced NAcc activity, mostly associated with impaired pleasure, as well as reduced activation of the caudate nuclei and the putamen, mainly associated with reward learning and reward prediction, respectively ${ }^{28,30}$. Taken together, these findings suggest a general state of hyposensitivity to rewards observed in depression, a characteristic that has been shown by different measurement approaches ${ }^{31,32}$.

\footnotetext{
*Most disorders currently categorized as anxiety disorders, obsessive compulsive disorder, threat- and stress-related disorders, and depression are thought to be threat-related disorders, but it is not possible to affirm that all cases that currently fulfill criteria for these disorders have are, indeed, threat-related disorders neither is possible to rule out the involvement of this survival function in other disorders, as threatening experiences are strongly related to virtually all types of psychiatric disorders ${ }^{20}$. Future studies on the reclassification of psychiatric disorders may shed light on this issue.
} 
Importantly, however, although these characteristics has been most extensively linked to depression, similar particularities in reward processing across different disorders has inspired some authors to seek for transdiagnostic markers that may transcend single diagnostic categories defined by current psychiatric nosologies ${ }^{29}$. These symptoms are also observed in many patients with PTSD and anxiety disorders that no not fulfill criteria for depression, especially in exacerbation phases or acutely exposed to stimuli related to the threatening object involved in their disorder, which is consistent with the proposition that characteristics like decreased sensitivity to rewards might be, at least in some cases, the effect of threats over the appetitive system.

\section{Effects of threat over the defensive and the appetitive systems}

In this paper, we described that a progressive sensitization to threats, facilitation of threat conditioning and generalization, and weaker extinction of defensive responses as some of the characteristic of DMSs. These are, therefore, some of the effects of threats over the defensive system itself.

We have also discussed that threat exposure can also affect other survival systems, such as the appetitive functions, in an orchestrated adaptation that optimizes defense $^{2}$. In general terms, appetitive engagements are suppressed not to compete with defense when this is a priority and many of the organismic resources usually involved in appetitive functions are recruited to work for defense. A good example of this reasoning is the NAcc, usually known to be involved in appetitive-related survival functions that, more recently, was shown to be a crucial part of learned active avoidance as well ${ }^{33}$.

Possibly for these reasons, stress impairs appetitive sensitivity, decreasing behavior based on positive reinforcement and producing an effect very similar to what is observed in depression. It has been shown that, under threat, dopamine activity in the mesolimbic pathway is

\section{REFERENCES}

1. LeDoux JE. Coming to terms with fear. Proc Natl Acad Sci. 2014;111(8):2871-8. doi: 10.1073/pnas.1400335111.

2. Corchs F, Schiller D. Threat-related disorders as persistent motivational states of defense. Curr Opin Behav Sci. 2019;26:62-8. doi: 10.1016/j.cobeha.2018.10.007.

3. LeDoux J. Rethinking the emotional brain. Neuron. 2012;73(4):653-76. doi: 10.1016/j.neuron.2012.02.004.

4. Insel T, Cuthbert B, Garvey M, Heinssen R, Pine DS, Quinn $\mathrm{K}$, et al. Research domain criteria (RDoC): toward a new classification framework for research on mental disorders. Am Psychiatric Assoc. 2010;167(7):748-51. doi: 10.1176/ appi.ajp.2010.09091379. reduced, decreasing reward-oriented activity, motivation and behavior and motivation, as well as the pleasure experienced in these situations ${ }^{34}$. If that situation persists long enough, though, the deprived appetitive need, such as food, grows in priority and the subject will eventually respond for it. After some water and food consumption, these needs fall below defense as priorities again, and the consummatory behaviors cease. This balance between survival priorities will fluctuate as described for as long as this environmental contingency persists.

Finally, even though it seems to exist a remarkable coincidence of the effects of threat over defensive and appetitive functions and systems and the vicissitudes of these systems in threat-related disorders, it is important to note, whereas the former is temporary, the latter is persistent. A few theoretical approaches to bridge this gap has been arisen (e.g. 2), but this area is still very poorly explored.

\section{CONCLUSION}

Current classifications of psychiatric disorders based on clinical consensus has shown to be fragile, with poor outcome prediction and inconsistent etiopathogenic findings. Initiatives like the RDoC aims to develop bottomup constructs, based solid biobehavioral constructs like those proposed herein. Modern research tolls have been making it possible to improve the knowledge regarding our defense and appetitive systems and how they are altered in many psychological states, including those considered a disorder. These findings propitiate a neurobiological understanding of the heightened sensitivity, conditionabiliy, and generalizability of threats, the weakened defensive regulation, and the reduced appetitive functions observed in these individuals. This view could point related sciences towards the right variables that need to be studied in order to improved prediction and control of these problems in strategies like prevention and treatment, as well as a better clinical management of individual cases in the clinical setting.

5. Perusini JN, Meyer EM, Long VA, Rau V, Nocera N, Avershal $\mathrm{J}$, et al. Induction and expression of fear sensitization caused by acute traumatic stress. Neuropsychopharmacology. 2016;41(1):45-57. doi: 10.1038/npp.2015.224.

6. Pavlov IP. Conditioned reflexes; an investigation of the physiological activity of the cerebral cortex. London: Oxford University Press: Humphrey Milford; 1927. p. xv.

7. Milad MR, Quirk GJ. Fear extinction as a model for translational neuroscience: ten years of progress. Annu Rev Psychol. 2012;63:129-51. doi: 10.1146/annurev. psych.121208.131631. 
Carui N, et al. Threat, its impacts over survival systems, and related behavioral disorders.

8. Kandel ER, Schwartz JH, Jessell TM, Biochemistry Do, Jessell MBT, Siegelbaum S, et al. Principles of neural science: New York: McGraw-Hill; 2000.

9. Ramirez F, Moscarello JM, LeDoux JE, Sears RM. Active avoidance requires a serial basal amygdala to nucleus accumbens shell circuit. J Neurosci. 2015;35(8):3470-7. doi: 10.1523/JNEUROSCI.1331-14.2015.

10. Mobbs D, Petrovic P, Marchant JL, Hassabis D, Weiskopf N, Seymour B, et al. When fear is near: threat imminence elicits prefrontal-periaqueductal gray shifts in humans. Science. 2007;317(5841):1079-83. doi: 10.1126/science.1144298.

11. Mobbs D, Marchant JL, Hassabis D, Seymour B, Tan G, Gray M, et al. From threat to fear: the neural organization of defensive fear systems in humans. J Neurosci. 2009;29(39):12236-43. doi: 10.1523/ JNEUROSCI.2378-09.2009.

12. Moscarello JM, LeDoux JE. Active avoidance learning requires prefrontal suppression of amygdala-mediated defensive reactions. J Neurosci. 2013;33(9):3815-23. doi: 10.1523/JNEUROSCI.2596-12.2013.

13. LeDoux JE. Emotion, memory and the brain. Sci Am. 1994;270(6):50-7.

14. Quirk GJ, Mueller D. Neural mechanisms of extinction learning and retrieval. Neuropsychopharmacology. 2008;33(1):56-72. doi: 10.1038/sj.npp.1301555.

15. Quirk GJ, Garcia R, González-Lima F. Prefrontal mechanisms in extinction of conditioned fear. Biol Psychiatry. 2006;60(4):337-43. doi: 10.1016/j.biopsych.2006.03.010.

16. Bouton ME. Context and behavioral processes in extinction. Learn Mem. 2004;11(5):485-94. doi: 10.1101/1m.78804.

17. Dunsmoor JE, Campese VD, Ceceli AO, LeDoux JE, Phelps EA. Novelty-facilitated extinction: providing a novel outcome in place of an expected threat diminishes recovery of defensive responses. Biol Psychiatry. 2015;78(3):203-9. doi: 10.1016/j.biopsych.2014.12.008.

18. Perusini JN, Fanselow MS. Neurobehavioral perspectives on the distinction between fear and anxiety. Learn Mem. 2015;22(9):417-25. doi: 10.1101/lm.039180.115.

19. Dillon DG, Rosso IM, Pechtel P, Killgore WD, Rauch SL, Pizzagalli DA. Peril and pleasure: An RDOC-inspired examination of threat responses and reward processing in anxiety and depression. Depress Anxiety. 2014;31(3):23349. doi: 10.1002/da.22202.

20. Chandan JS, Thomas T, Bradbury-Jones C, Russell R, Bandyopadhyay S, Nirantharakumar K, et al. Female survivors of intimate partner violence and risk of depression, anxiety and serious mental illness. Br J Psychiatry. 2019:16. doi: 10.1192/bjp.2019.124.

21. Cisler JM, Koster EH. Mechanisms of attentional biases towards threat in anxiety disorders: an integrative review. Clin Psychol Rev. 2010;30(2):203-16. doi: 10.1016/j. cpr.2009.11.003.
22. Etkin A, Wager TD. Functional neuroimaging of anxiety: a meta-analysis of emotional processing in PTSD, social anxiety disorder, and specific phobia. Am J Psychiatry. 2007;164(10):1476-88. doi: 10.1176/appi. ajp.2007.07030504.

23. Shin LM, Rauch SL, Pitman RK. Amygdala, medial prefrontal cortex, and hippocampal function in PTSD. Ann New York Acad Sci.. 2006;1071(1):67-79. doi: 10.1196/ annals.1364.007.

24. Skinner BF. Science and human behavior. New York: Macmillan; 1953.

25. Olds J, Milner P. Positive reinforcement produced by electrical stimulation of septal area and other regions of rat brain. J Comp Physiol Psychol. 1954;47(6):419-27.

26. Berridge $\mathrm{KC}$, Kringelbach ML. Pleasure systems in the brain. Neuron. 2015;86(3):646-64. doi: 10.1016/j. neuron.2015.02.018.

27. Kelley AE, Berridge KC. The neuroscience of natural rewards: relevance to addictive drugs. J Neurosci. 2002;22(9):3306-11. doi: 20026361.

28. Dillon DG, Rosso IM, Pechtel P, Killgore WD, Rauch SL, Pizzagalli DA. Peril and pleasure: an rdoc-inspired examination of threat responses and reward processing in anxiety and depression. Depress Anxiety. 2014;31(3):23349. doi: 10.1002/da.22202.

29. Whitton AE, Treadway MT, Pizzagalli DA. Reward processing dysfunction in major depression, bipolar disorder and schizophrenia. Curr Opin Psychiatry. 2015;28(1):7-12. doi: 10.1097/YCO.0000000000000122.

30. Admon R, Pizzagalli DA. Dysfunctional Reward Processing in Depression. Curr Opin Psychol. 2015;4:114-8. doi: 10.1016/j.copsyc.2014.12.011.

31. Bijttebier P, Beck I, Claes L, Vandereycken W. Gray's Reinforcement Sensitivity Theory as a framework for research on personality-psychopathology associations. Clin Psychol Rev. 2009;29(5):421-30. doi: 10.1016/j. cpr.2009.04.002.

32. Nusslock R, Alloy LB. Reward processing and moodrelated symptoms: an RDoC and translational neuroscience perspective. J Affect Disord. 2017;216:3-16. doi: 10.1016/j. jad.2017.02.001.

33. Ramirez F, Moscarello JM, LeDoux JE, Sears RM. Active avoidance requires a serial Basal amygdala to nucleus accumbens shell circuit. J Neurosci. 2015;35(8):3470-7. doi: 10.1523/JNEUROSCI.1331-14.2015.

34. Pezze MA, Feldon J. Mesolimbic dopaminergic pathways in fear conditioning. Progr Neurobiol. 2004;74(5):301-20. doi: 10.1016/j.pneurobio.2004.09.004.

Received: June 15, 2019

Accepted: July 10, 2019 